\title{
¿̇RESULTA CONSTITUCIONAL UN SISTEMA DE PLAZOS SIN EXPRESIÓN DE CAUSA EN EL ORDENAMIENTO JURÍDICO CHILENO?'
}

\author{
Is abortion on-demand allowed \\ by the Constitution of Chile? \\ JOSÉ ÁNGEL FERNÁNDEZ CRUZ² \\ Universidad Austral de Chile \\ josefernandez@uach.cl \\ YANIRA ZÚÑIGA AÑAZCO ${ }^{3}$ \\ Universidad Austral de Chile \\ yzuniga@uach.cl
}

Cómo citar/Citation

Fernández Cruz, J. Á. y Zúñiga Añazco, Y. (2020).

¿́Resulta constitucional un sistema de plazos sin expresión

de causa en el ordenamiento jurídico chileno?

Anuario Iberoamericano de Justicia Constitucional, 24(1), 177-206.

doi: https://doi.org/10.18042/cepc/aijc.24.06

Resumen

La cuestión que trata el estudio es si, ante un eventual proyecto legislativo que regule un sistema de despenalización parcial del aborto articulado en plazos sin ex-

1 El presente estudio se ha realizado en el marco del proyecto de investigación «La influencia de la jurisprudencia del Tribunal Europeo de Derechos Humanos en las decisiones del Tribunal Constitucional», financiado por el Ministerio de Fomento y Competitividad, España (DER 2015-67512).

2 Profesor de Derecho Penal, Universidad Austral de Chile, Campus Isla Teja s/n, Valdivia, fono: 5663221567 . Autor destinatario.

3 Profesora de Derecho y Género, Universidad Austral de Chile, Campus Isla Teja s/n, Valdivia, fono: 5663221567. 
presión de causa, este resulta conforme con la Constitución Política de la República. Nuestra posición sostiene que - a partir de la Sentencia del Tribunal Constitucional de 28 de agosto de 2017, Rol 3729-17-CPT, relativa a la Ley No 21.030 de 23 de septiembre de 2017, «que regula la despenalización de la interrupción voluntaria del embarazo en tres causales», y de la jurisprudencia emanada de la Corte Interamericana de Derechos Humanos - no se requería una reforma constitucional para incluir este modelo en nuestro derecho positivo.

\section{Palabras clave}

Aborto; estatus constitucional del nasciturus; derechos sexuales y reproductivos.

\section{Abstract}

This study addresses the question whether a legislative draft that legalized abortions performed during the first 14 weeks of pregnancy would be allowed by the Chilean Constitution. Our position, based on the Constitutional Court Sentence, Rol 3729-17-CPT, regarding Act $\mathrm{N}^{\circ} 21.030$ that legalized abortions on three grounds, and the jurisprudence of the Inter-American Court of Human Rights, maintains that a constitutional amendment would not be necessary in order to legalize abortion in the first 14 weeks of pregnancy.

\section{Keywords}

Abortion; legal status of fetus; sexual and reproductive rights. 


\section{SUMARIO}

I. INTRODUCCIÓN. II. LA NECESIDAD DE DISCUTIR LA INCLUSIÓN DE UN SISTEMA DE PLAZOS SIN EXPRESIÓN DE CAUSA. III. LA STC SOBRE INDICACIONES ANTE UN DEBATE SOBRE UN MODELO DE PLAZOS: 1. Criterios interpretativos y determinación del conflicto constitucional. 2. El estatuto constitucional «del que estar por nacer». 3. La obligación constitucional de protección penal «del que está por nacer». 4. La constitucionalización de los derechos reproductivos de la mujer. 5. El establecimiento de un plazo en la indicación jurídica. 6. La ponderación entre los derechos sexuales y reproductivos de la mujer y el nasciturus como bien jurídico de «la mayor relevancia». IV. EL SISTEMA INTERAMERICANO DE PROTECCIÓN DE DERECHOS HUMANOS. V. A MODO DE CONCLUSIÓN. BIBLIOGRAFÍA.

\section{INTRODUCCIÓN}

Con fecha 28 de agosto de 2017, el Tribunal Constitucional (TC) de Chile resolvió la controversia jurídica en torno a la Ley 21.030 (D.O. 23 de septiembre de 2017), declarando la constitucionalidad de la despenalización de la interrupción voluntaria del embarazo en tres causales: peligro para la vida de la madre, inviabilidad fetal de carácter letal y violación. Este nuevo régimen de indicaciones reemplazó al sistema de prohibición absoluta que regía desde el final de la dictadura militar. Sin embargo, a poco de entrar en vigencia, ya han surgido voces que proponen el establecimiento de un modelo de plazos sin expresión de causa (en lo sucesivo, modelo o sistema de plazos).

Este trabajo no pretende discutir todos los razonamientos esgrimidos por la doctrina y la jurisprudencia chilenas, a favor o en contra de la constitucionalidad de una eventual reforma en tal sentido. Su propósito es identificar y analizar una serie de líneas argumentativas, desarrolladas por el TC en la sentencia antes referida (en lo sucesivo, STC sobre indicaciones) y por la Corte Interamericana de Derechos Humanos (CIDH) en su jurisprudencia reciente, que pueden tener incidencia en tal discusión.

El estudio se articulará en tres apartados. En el primero, expondremos las razones por las que resulta necesario discutir sobre la inclusión de un sistema de plazos en el derecho chileno; en el segundo, profundizaremos en los fundamentos de la STC sobre indicaciones que pueden jugar a favor de la conformidad 
de este modelo con la Constitución Política de la República (en adelante CPR), y, en el tercero, evaluaremos la compatibilidad del sistema de plazos con la jurisprudencia del Sistema Interamericano de Derechos Humanos.

Como presupuesto de estudio tomaremos el modelo español de interrupción del embarazo que combina un sistema de plazos (14 semanas) sin expresión de causa con uno de indicaciones por razones médicas (terapéutica y embriopática), acompañado de unos mecanismos destinados a asegurar una toma de decisión informada por parte de la mujer ${ }^{4}$.

\section{LA NECESIDAD DE DISCUTIR LA INCLUSIÓN DE UN SISTEMA DE PLAZOS SIN EXPRESIÓN DE CAUSA}

Antes de enumerar algunas de las razones que justifican una discusión sobre la constitucionalidad de un sistema de plazos, debemos clarificar qué modelo o modelos de regulación y despenalización del aborto existen en Chile tras la Ley $\mathrm{N}^{\circ}$ 21.030. Si bien es cierto que, tras la reforma, Chile se encuadra, desde una perspectiva formal, dentro del modelo de exención de la responsabilidad penal ligada a indicaciones que deben probarse por el sistema de salud (Willenmann et al., 2017: 10) (en lo sucesivo, modelo de indicaciones), desde una perspectiva material, estamos ante un modelo de cuasiprohibición simbólico del aborto sin cobertura socio sanitaria, en el que las excepciones de punición no solo se encuentran en las causales establecidas en el Código Sanitario (en lo sucesivo CS), sino también en las comprendidas en el sistema general de causas de justificación o exculpación regulado en el Código Penal (CP).

Dentro de las razones que justifican un debate constitucional y político-criminal sobre una eventual reforma legislativa que regule un sistema de plazos, podemos destacar cuatro. La primera toma como referencia la evolución del derecho comparado sobre la regulación del aborto. La gran mayoría de los sistemas jurídicos que, en la actualidad, contemplan un sistema de plazos adoptaron previamente un sistema de indicaciones. Por otra parte, el sistema de plazos se viene extendiendo progresivamente desde el último tercio del siglo xx y ha ganado aceleradamente terreno en el debate constitucional

4 LO 2/2010 de 3 de marzo de 2010, de salud sexual y reproductiva y de la interrupción voluntaria del embarazo. No obstante, a fecha de hoy, se encuentra pendiente la resolución por parte del Tribunal Constitucional de un recurso de inconstitucionalidad (núm. 4523-2010), promovido por setenta y un Diputados del Grupo Parlamentario Popular del Congreso, salvo una cuestión incidental, en la que se deniega la suspensión de varios preceptos (Auto 90/2010, de 14 de julio de 2010). 
en las últimas dos décadas 5 . Si se parte de la base — como aquí se hará- de que el sistema de plazos constituye en la actualidad el mejor modelo político criminal para abordar la problemática del aborto y que goza de una justificación constitucional ampliamente aceptada, entonces habría sido mejor haber discutido, de entrada, dicho sistema en vez de regular un modelo de indicaciones. En efecto, el primero tiene varias ventajas sobre el segundo: evita que un número nada despreciable de mujeres vean limitado sus derechos sexuales y reproductivos; disminuye notablemente el peligro a la salud e integridad física de estas y garantiza una protección incremental de la vida prenatal. El resurgimiento del debate por un sistema de plazos a menos de un año de la entrada en vigor de la Ley No 21.030, al alero de las recientes movilizaciones feministas en Chile y con un claro impacto de la discusión legislativa llevada a cabo recientemente en Argentina, corroboran que existe un aumento explosivo de la demanda ciudadana en este sentido ${ }^{6}$.

La segunda razón se relaciona con las consecuencias político-criminales de la Ley 21.030. La principal de ellas no reside en el hecho de que, en determinados contextos, el aborto en Chile se encuentre permitido y garantizado por el sistema de salud, sino, más bien, en el mantenimiento del statu quo en el tratamiento estatal de las interrupciones voluntarias del embarazo. Es decir, en la pervivencia de un modelo que hemos definido como una cuasiprohibición penal simbólica sin cobertura sanitaria. Si bien esta ley va a permitir que, en ciertos casos, algunas mujeres no se vean sometidas a la amenaza de una pena y las mantendrá a salvo de los riesgos que comporta la realización de un aborto ilegal, los casos de aborto fundamentados en las tres causales de la ley van a ser, estadísticamente hablando, poco relevantes ${ }^{7}$, en contraste con el reducido número de mujeres condenadas por este delito ${ }^{8}$.

5 Véase en América Latina, Bergallo (2016: 291-321) y, en Europa, Laurenzo, (2012: 6).

6 En todo caso, tanto la regulación del aborto como las prácticas sociales asociadas a este no han obedecido en la historia de Chile a un modelo prohibicionista. Véase en extenso y doctrina citada en: Dides et al. (2016: 149-155).

7 En Chile, las estimaciones más conocidas oscilan entre 200.000 y 60.000 abortos anuales. En el año 2007 se ha estimado una tasa de 50 abortos inducidos por cada 1.000 mujeres en edad fértil (Dides et al., 2016: 155, n. 22 a 24). El aborto constituye en Chile la tercera causa de mortalidad materna. Ministerio de Salud, Presentación Programa Nacional Salud de la Mujer, Temuco, 2014, citado por Dides et al. (2016: 157).

8 Entre 2010 a 2014 se han procesado a 182 mujeres y 89 hombres, las condenas ascienden, en el mismo periodo, a 73 y, el año 2015, 12 personas (solo hombres) se encontraban cumpliendo una pena privativa de libertad (Dides et al., 2016: 157-160). 
Por otra parte, es claro que la mayoría de las mujeres que quieren abortar lo hacen por razones que nada tienen que ver con las causales reguladas por la Ley 21.030. Algunas lo hacen por problemas económicos, otras por embarazos no deseados, otras porque son muy jóvenes para criar un niño, otras porque prefieren dedicarse a sus estudios o a su carrera profesional y otras, simplemente, porque no quieren continuar con el embarazo9. Debido a esta larga y heterogénea lista de factores que inciden en la interrupción voluntaria del embarazo, las grandes opciones político-criminales se bifurcan en dos caminos: instaurar un sistema que afronte de manera efectiva el aborto o continuar con una protección penal simbólica de la vida prenatal unida a una desprotección socio-sanitaria por parte del Estado.

La tercera razón es de tipo consecuencialista. Puede augurarse un fracaso del modelo regulativo actual del aborto en Chile a la hora de disminuir las tasas de aborto, lo que conlleva un compromiso de la función simbólica del derecho penal, debido fundamentalmente a la existencia de un divorcio deliberado entre la representación jurídico-penal vigente y la representación social que trasunta la práctica cotidiana sobre el aborto (Dalbora, 2012: 22).

La cuarta razón que queremos plantear a favor de la discusión sobre la inclusión de un modelo de plazos radica en consideraciones ligadas a la protección de la salud reproductiva de las gestantes. El Estado chileno reconoce el derecho constitucional a la salud sin discriminación por razón de sexo (art. 19 $\mathrm{N}^{\circ} 9 \mathrm{CPR}$ en relación con el art. 19 No 2), sin embargo, la salud reproductiva de mujeres, niñas y adolescentes continúa sin ser adecuadamente garantizada. En otras palabras, resulta discutible que Chile cumpla con las exigencias mínimas de protección de los derechos reproductivos de las mujeres en la medida en que, aun bajo el imperio de la Ley 21.030, las mujeres no son consideradas agentes morales autónomos capaces de adoptar decisiones sobre su propio cuerpo y, en definitiva, sobre su propio proyecto de vida. En contraste, los estándares internacionales elaborados por distintos comités supervisores de tratados internacionales (Comité de DDHH, Comité de la CEDAW) sostienen que la afectación de los derechos de las mujeres no solo se produce en los casos de regímenes absolutamente prohibitivos, sino también en el marco de sistemas de indicaciones muy conservadores o ampliamente no observados en la práctica. De suerte que, aunque la aprobación de un sistema de plazos no es, por sí misma, garantía de la protección de los derechos de las mujeres, ofrece mejores posibilidades de eficacia debido a que transforma la autonomía

9 Un indicador ilustrativo es el descenso sostenido de la tasa de natalidad. En el Censo 2017 la paridad media fue 1,3, mientras que en el Censo 2002 se situó en 1,6 hijos por mujer (Instituto Nacional de Estadística, 2018: 13). 
procreativa de las mujeres, de una excepción a una regla general (Zúñiga, 2018: 91-111). A lo anterior debemos añadir, que, si bien los pronunciamientos de los órganos internacionales de derechos humanos consideran como tratos crueles, inhumanos y degradantes los casos de imposición de embarazos en contextos estatales que no contemplan un modelo de indicaciones (Comité de Derecho Humanos, 2011), la práctica sistemática de abortos consentidos sin una adecuada asistencia socio-sanitaria y en condiciones de clandestinidad - como ocurre mayoritariamente en Chile- puede ser entendida también como una forma de trato cruel, inhumano y degradante: «una forma de poder «biopolítica», cuya meta es administrar la salud sexual y reproductiva de las mujeres» (Dides, 2016: 181).

Efectivamente, los complejos problemas que plantea la regulación del aborto desde las perspectivas moral, constitucional, convencional, político-criminal, entre otras, ni mucho menos se han solucionado con la actual reforma.

\section{LA STC SOBRE INDICACIONES ANTE UN DEBATE SOBRE UN MODELO DE PLAZOS}

Antes de abordar el contenido de la sentencia, es conveniente mencionar dos características de la justicia constitucional chilena.

La primera se relaciona con el peso de las consideraciones de carácter político y cultural en la jurisprudencia del TC, en cierto desmedro de las consideraciones meramente dogmáticas. Aunque no abordaremos en detalle los aspectos políticos e institucionales de la jurisprudencia del TC chileno, es importante destacar, de acuerdo con Bascuñán (2004: 43-89) que, hasta la sentencia sobre indicaciones, la jurisprudencia constitucional chilena había estado marcada por una cultura predominantemente conservadora católica y contramoderna en la que convergen una determinada concepción moral del nasciturus con una obligación constitucional de punición ${ }^{10}$.

Una segunda característica de la justicia constitucional chilena se relaciona con la inexistencia de un modelo de autoprecedente constitucional, en un sentido fuerte. Así, incluso, si aceptamos como correcta la tesis de que la

10 Esta jurisprudencia ha tenido como objeto de controversia decisiones gubernativas relativas a la distribución de píldoras de emergencia: Sentencias de la Corte Suprema Philippi Izquierdo con Instituto de Salud Pública y Centro Juvenil Ages de 30 de agosto de 2001, Rol 850-2001 y Centro Juvenil Ages contra Instituto de Salud Pública de 28 de diciembre, Rol 5839-2002 y STC sobre la píldora del día después. 
sentencia sobre indicaciones, al no contar con la mayoría de los votos sobre la interpretación del art. $19 \mathrm{~N}^{\circ} 1$, inc. $2^{\circ} \mathrm{CPR}$, no constituiría el precedente más inmediato sobre el concepto de nasciturus y, en particular, no alteraría el precedente establecido en la sentencia del TC que se pronunció sobre la entrega de la píldora del día después, en la que se declara que la protección constitucional de este se inicia desde el «momento mismo de la concepción» ${ }^{11}$, nada impide que, en el futuro, el TC tome como referencia cualquiera de los razonamientos de la STC sobre indicaciones a la hora de dirimir la constitucionalidad de un eventual modelo de plazo (Fernández y Núñez, inédito).

\section{CRITERIOS INTERPRETATIVOS Y DETERMINACIÓN DEL CONFLICTO CONSTITUCIONAL}

La sentencia dedica dos capítulos específicos a los criterios interpretativos o, como los denomina el propio TC, a los «elementos que van a guiar su razonamiento» constitucional. Estos criterios resultan especialmente relevantes en una eventual discusión sobre un modelo de plazos. Así, el TC menciona expresamente los principios institucionales de corrección funcional, presunción de constitucionalidad y de dinamicidad en la interpretación constitucional. Además, rechaza el originalismo, como único o principal criterio interpretativo de la Constitución, al menos en cuestiones relacionadas con el aborto $^{12}$. Dentro de estos criterios, debemos destacar el de dinamicidad social o adecuación a la realidad social, ya que supone el camino de entrada a los cambios legales y de derecho internacional que han reconocido y fortalecido la protección de los derechos sociales y reproductivos de la mujer. Constituye también la forma en que las percepciones sociales respecto un problema o conflicto constitucional inciden en la interpretación de los tribunales constitucionales (cons. $21^{\circ}-28^{\circ}$ ).

Además, el fallo incorpora el principio penal de ultima ratio y el de pluralismo político como metacriterios de interpretación constitucional, del que

11 STC de 18 de abril de 2008, Rol 740/2007, sobre las «Normas Nacionales de Control de la Fertilidad» (Decreto del Ministerio de Salud chileno, núm. 48 del 26 de enero del 2007), coloquialmente conocida como la sentencia de «la píldora del día después», cons. $46^{\circ}$ a $60^{\circ}$. A partir, entre otras razones, de esta comprensión del nasciturus, el TC declaró inconstitucional la distribución de los denominados anticonceptivos de emergencia por parte del sistema público de salud.

12 En todo caso, la propia sentencia pone de manifiesto que la Comisión de Estudio de la Nueva Constitución se decantó "por asegurar a nivel constitucional el derecho a la vida y a la integridad física y psíquica de la persona, el sujeto nacido, y dejar entregada al legislador la facultad de proteger la vida del que está por nacer [...]» (cons. $\left.31^{\circ}\right)$. 
se derivan una serie de derechos, garantías y prohibiciones constitucionales, entre las que destacan la prohibición de imponer un determinado pensamiento (moral, ideología o religión) al conjunto de la ciudadanía (cons. $30^{\circ}$ ).

\section{EL ESTATUTO CONSTITUCIONAL «DEL QUE ESTAR POR NACER»}

A nuestro entender, el estatuto jurídico del nasciturus no resulta decisivo para juzgar la constitucionalidad de los sistemas de indicaciones, ya que, incluso si se aceptara que este ostenta la condición de persona, existen buenas razones para justificar o exculpar las interrupciones del embarazo. Sin embargo, la cuestión de si el nonato es o no persona adquiere relevancia a la hora de afrontar un sistema de plazos sin expresión de causa. La noción de persona permite interrogarnos sobre las propiedades relevantes que una vida humana debe satisfacer para adscribirle el derecho a la vida y sobre el tipo de protecciones que paradigmáticamente rodean este derecho ${ }^{13}$. Por otro lado, permite identificar qué condiciones, distintas de los casos vinculados a las indicaciones, pueden justificar una acción destructiva de la vida prenatal. Los casos constitutivos de las indicaciones configuran permisos excepcionales para abortar que reenvían también a circunstancias excepcionales: embarazos demasiado gravosos para las gestantes que comprometen de manera grave derechos tales como la vida, la salud o la integridad psíquico-física. Al contrario, en los sistemas de plazo la afectación de los derechos de las mujeres es menos intensa, mientras que los intereses asociados a la protección de la vida gestacional dejan de ser meramente potenciales. Entonces, la discusión constitucional sobre los criterios que deben guiar la ponderación de los intereses en juego - en particular, el estatus del nasciturus — se vuelve ineludible ${ }^{14}$.

La STC sobre indicaciones comienza su argumentación con una afirmación sobre el estatus constitucional del nasciturus que, hasta tiempos recientes, era impensable: «[...] la Constitución no le otorga al que está por nacer la categoría de persona. Ello no obsta a que sea un bien jurídico de la mayor relevancia» (cons. 40-50). El TC parte de la premisa de que el concepto constitucional de persona coincide con el establecido en las normas civiles que regulan

13 En cuanto a la necesidad de delimitar constitucionalmente el estatus jurídico del embrión y feto, véase, en extenso, Mañalich (2014: 305-303). No obstante, debe advertirse que, por más de ochenta años, la Corte Suprema estadounidense ha dirimido sobre las regulaciones de los Estados sobre el aborto sin decidir si o cuándo un feto puede ser considerado como una persona (Rubenfeld, 1991: 599-635).

14 Así, el sistema de indicaciones ha encubierto, por la vía de abordar el aborto como un conflicto entre los derechos reproductivos y sexuales de la mujer y el supuesto interés del feto, la determinación del estatus jurídico del nasciturus (Mañalich, 2014: 312). 
esta y sus derechos. Así, a partir de una interpretación sistemática de las disposiciones constitucionales y de otros cuerpos normativos, llega a la conclusión de que el estatus jurídico de la persona comienza con el nacimiento. Sin duda, el principal fundamento de esta afirmación lo encontramos en el propio art. $19 \mathrm{~N}^{\circ} 1$ de la CPR que diferencia expresamente entre "persona» y «el que está por nacer» (por todos, Bascuñán, 2016: 194). El TC descarta también que, bajo el texto constitucional vigente, la idea de persona sea equivalente a la expresión naturaleza humana que ocupa el inciso $2^{\circ}$ del art. 5 de la CPR, y enfatiza que la naturaleza humana a la que se refiere esta última disposición es aquella protegida por los derechos establecidos en la Constitución o en los tratados internacionales (cons. 74).

Cabe mencionar que en la STC de indicaciones el TC solo determina cuándo cesa la condición de nasciturus (con el parto y la separación total del claustro materno), pero se abstiene de indicar qué hito biológico marca el comienzo de esta condición, en contraste con su sentencia sobre la píldora del día después que había retrotraído el comienzo de la protección jurídica de la vida prenatal al momento de la concepción. Por tanto, una cuestión que no aclara el fallo sobre indicaciones es en qué momento de la gestación el nonato adquiere la condición de nasciturus, es decir, desde qué momento comienza el régimen de protección del art. 19.1 , inc. $2^{\circ} \mathrm{CPR}$.

La ausencia de pronunciamiento del TC sobre esta cuestión en la STC sobre indicaciones descansa en dos tipos razones que le sirven, a su vez, para vertebrar un modelo de deferencia al legislador en materia de protección de la vida prenatal. El primer orden de razones, de corte competencial, toma nota del hecho de que la CPR no ha establecido una regla explícita sobre el inicio de la protección constitucional de la vida prenatal y, en cambio, ha mandatado al legislador para regular dicha protección. Mientras que el segundo orden de razones, de corte epistémico e institucional, constata la existencia de una entreverada controversia científica, moral y política en relación con este asunto. Según el TC, no le corresponde a la jurisdicción constitucional pronunciarse sobre esta cuestión, solo cabe reconocer al legislador la potestad de concretar el comienzo de la protección del nasciturus a partir, entre otros criterios, del principio de protección incremental del embrión/feto ${ }^{15}$. Esto significa que el

15 Aquí toma como referencia la propia legislación chilena, en la que se establece diversos grados de protección del derecho a la vida como, por ejemplo, en Ley $\mathrm{N}^{\circ} 19.451$, de 29 de marzo de 1996, sobre trasplantes de órganos, la jurisprudencia constitucional comparada y la jurisprudencia de la Corte Interamericana de Derechos Humanos en el caso Artavia Murillo vs. Costa Rica (cons. 19º). No obstante, respecto de esta última jurisprudencia, el TC descartó de plano pronunciarse sobre la forma en la que las 
legislador podría, a priori, compaginar el contenido normativo del art. $19.1^{\circ}$, inc. $2^{\circ} \mathrm{CPR}$ con una ley de despenalización parcial del aborto articulado en modelo de plazos sin expresión de causa.

Así, el TC parece delegar en el legislador el momento en que el proceso biológico de la vida humana adquiere el estatus de nasciturus. Ahora bien, puede entenderse que el art. $19.1^{\circ}$, inc. $2^{\circ} \mathrm{CPR}$ delega de manera clara solo la forma o manera en que ha de protegerse al que está por nacer — es decir, por ley-, pero dicha delegación no incluye necesariamente la determinación de cuándo el proceso biológico de la vida humana adquiere el estatus de nasciturus.

Una manera adecuada de afrontar este problema es diferenciar entre la determinación general del estatus jurídico del «que está por nacer» y la concreción de este estatus en cada problema o cuestión jurídica (derechos hereditarios, investigación embrionaria, aborto, etc.). A partir de esta distinción pueden concurrir varias relaciones competenciales entre el legislador y el TC. La primera, y más deferente con el legislador, sería aquella en que la competencia para determinar tanto el estatus general como los diferentes estatus concretos del nasciturus corresponde al legislador, debido a la menor relevancia constitucional de este. Por tanto, esta posición solo requiere una protección de la vida prenatal de carácter formal o procedimental (la ley). La segunda consistiría en atribuir al TC el establecimiento del estatus general de nasciturus, es decir, la delimitación de un espacio de tiempo del proceso biológico de la vida humana en el que debe existir algún tipo de protección legal, correspondiendo su concreción con exclusividad al legislador. La tercera consistiría en atribuir al TC, además del establecimiento del estatus jurídico general del nasciturus, el control de constitucionalidad, en este caso negativo, sobre un determinado estatus jurídico del nasciturus establecido por una ley.

Pero con independencia de la postura que se adopte, el art. $19.1^{\circ}$, inc. $2^{\circ}$ CPR permite, y de hecho así sucede, que puedan convivir en nuestro ordenamiento jurídico varios estatus jurídicos del nasciturus. Al igual que ocurre con la determinación de la capacidad jurídica, en la determinación del estatus jurídico del nasciturus no existe una única o absoluta respuesta, ya que esta puede variar dependiendo de cuestiones morales, éticas, médicas, fácticas o criminológicas, etc. (Rubenfeld, 1991: 601). En nuestro derecho positivo existe una regla general de capacidad jurídica, que coincide con los 18 años (art. 26 CC), que coexiste con otras reglas de capacidad jurídica para actos específicos. Por

sentencias de tribunales internacionales o las observaciones o recomendaciones emanadas de los órganos de control de tratados internacionales repercuten en el sistema constitucional chileno (cons. $10^{\circ}$ ). 
ejemplo, a los 14 años se adquiere la capacidad en materia de libertad sexual (art. 363 CP), y a los 35 años se adquiere la capacidad para ejercer ciertas funciones públicas, como ser Presidente de la República (art. 25 CPR) o Senador de la República (art. 50 CPR). Por tanto, la cuestión fundamental no consiste tanto en determinar un estatus jurídico del nasciturus, único y universal, sino establecer para cada problema jurídico que se plantee un momento en el que el nasciturus adquiere una determinada relevancia jurídica ${ }^{16}$.

Asumido, por tanto, que puede existir un estatus penal-constitucional del nasciturus diferenciado, la compatibilidad de un modelo de plazos sin expresión de causa con el art. $19.1^{\circ}$, inc. $2^{\circ} \mathrm{CPR}$ puede abordarse desde dos perspectivas. La primera consiste en negar al embrión antes de las 14 semanas la condición, no solo el estatus de persona, sino también de nasciturus porque carecería tanto de una esfera de autonomía similar a la establecida a los nacidos como del carácter de bien o interés jurídico de especial relevancia constitucional. Esta tesis puede asentarse en la interpretación del tenor literal del art. $19.1^{\circ}$, inc. $2^{\circ} \mathrm{CPR}$, ya que este precepto incluye un elemento de proximidad con el hecho biológico del nacimiento («el que está por nacer») que dejaría fuera de su campo semántico no solo el embrión preimplantacional, sino también el implantado. La segunda perspectiva consiste en reconocer que el embrión o feto antes de las 14 semanas constituye un bien o interés de relevancia constitucional, pero que, al entrar en conflicto con los derechos sexuales y reproductivos de la mujer, estos ostentan un mayor peso (Rubenfeld, 1991: 613 y Bascuñán, 2016: 175).

En todo caso, y de acuerdo con Queralt (2011: 4-5), cabe preguntarse si la vida del nasciturus es realmente el bien jurídico protegido en la prohibición del aborto. Aunque el objeto material sobre el que recae una acción abortiva sea la vida prenatal, si asumimos que el nasciturus no es titular de ningún derecho subjetivo, el bien jurídico protegido debe ser diferente al objeto sobre el que recae la acción. Al excluirse a la mujer, ya que ha concurrido su consentimiento, solo cabe como titular del bien jurídico a la sociedad en su conjunto la que tiene un «interés social en su propia perpetuación mediante la protección de lo que se da en llamar spes vitae, interés que, si no es contemplado desde una perspectiva racista, resulta perfectamente legítimo" (ibid.: 5). Ahora bien, si este es el interés protegido, entonces debe ser ponderado con los derechos de

16 La STC española 53/1985 (FJ 5) apunta en este sentido, al establecer que en la fase de desarrollo intrauterino se van produciendo «cambios cualitativos de naturaleza somática y psíquica que tienen un reflejo en el estatus jurídico público y privado del sujeto vital» entre los que destaca el momento en que este «es susceptible de vida independiente de la madre». 
autonomía de la mujer y, en la medida que no se vea un peligro real y efectivo, deben prevalecer estos últimos. Huelga decir que la adopción de un sistema de plazos en diversos países no ha tenido como consecuencia la puesta en peligro del equilibrio demográfico, incluso en algunos casos han disminuido el número de abortos (ibid.).

En el caso de que consideremos que el embrión antes de las 14 semanas se encuentra protegido por el art. $19.1^{\circ}$, inc. $2^{\circ} \mathrm{CPR}$, debe tenerse presente que tal disposición consagra un (meta) principio de exigibilidad diferenciada de la prohibición de atentar contra seres humanos no nacidos. La obligación constitucional de protección establecida en el citado precepto no busca establecer un derecho subjetivo a la vida, sino un interés de relevancia constitucional: una declaración del nasciturus como objeto de protección forzosa, pero que, a la vez, debe ser menor que la establecida a la persona (Bascuñán, 2004: 43-89).

$\mathrm{Al}$ igual que pueden coexistir diferentes estatus normativos del no nacido, nada impide que se establezca un nuevo hito empírico a partir del cual comience la protección penal dispensada por las figuras penales de aborto.

En cierta manera, el sistema de plazos se aproxima a una concepción (neo) lockeanista que concibe a la vida humana a partir de ciertas condiciones psicológicas, en contraposición con el denominado animalismo que entiende la vida humana como proceso biológico que, normalmente, comienza con la nueva célula que se produce a partir de la unión del gameto masculino con el gameto femenino (Paez, 2015: 243-258).

La posición mayoritaria lockeanista entiende que el feto se convierte en un ente mínimamente consciente cuando se producen las primeras las relaciones neuronales en la corteza cerebral (corticocentric perspective), es decir, cuando el feto es susceptible de experimentar dolor: no antes de las 23 semanas ni después de las 30 semanas de gestación (Lee, 2005: 947-954). No obstante, existe una tesis emergente (mesoencephalic perspective) que establece este primer momento de conciencia en la funcionalidad de algunas estructuras neuronales, situadas en el tronco encefálico (entre las 20 y 22 semanas de gestación $)^{17}$.

Como puede observarse, el modelo de plazos propuesto (hasta las 14 semanas de gestación) fija la protección en un momento anterior en la que el feto puede experimentar dolor. Su justificación puede encontrarse en el principio de precaución, a saber, en asumir una posición conservadora respecto al momento en el que feto podría experimentar una forma básica o rudimentaria de consciencia. Al igual que el hito del nacimiento (Mañalich, 2014: 328),

17 Véase, en extenso, Doctor on Fetal Pain (2013). 
este adelantamiento del plazo constituye una norma práctica, que minimiza el riesgo de errar sobre si un embrión o feto se corresponde con las propiedades que convierten a este en un interés de especial protección jurídica ${ }^{18}$.

\section{LA OBLIGACIÓN CONSTITUCIONAL DE PROTECCIÓN PENAL «DEL QUE ESTÁ POR NACER»}

El TC sostiene, de acuerdo con parte de la doctrina chilena (Bascuñán, 2016; Hernández, 2016; Undurraga, 2013), que el art. 19. $1^{\circ}$, inc. $2^{\circ} \mathrm{CPR}$ no establece una obligación constitucional de protección penal, sino una de carácter general que puede concretarse en una ley civil, laboral, de seguridad social, etc. Tanto la dicción literal del art. $19 \mathrm{~N}^{\circ} 1$ inc. $2^{\circ} \mathrm{CPR}$ como una interpretación sistemática del conjunto de disposiciones constitucionales permiten concluir que la CPR ha delegado en el legislador «la prerrogativa de punición (artículos 19, $\mathrm{N}^{\circ} 3$ y $63 \mathrm{~N}^{\circ} 3 \mathrm{CPR}$ )» (cons. $45^{\circ}-59^{\circ}$ ).

Con todo, si entendiéramos que sí existe una obligación de penalizar el aborto, pero que, en principio, queda en manos del legislador la manera e intensidad de llevarla a cabo, podemos llegar a la conclusión de que un sistema de plazos sin expresión de causa cumpliría un eventual mandato de criminalización abierto o laxo, ya que, como ocurre en la práctica totalidad de los ordenamientos jurídicos que adoptan este modelo, se contempla una serie de figuras penales que castigan aquellos casos en que se interrumpe el embarazo, más allá de los plazos o indicaciones expresamente reguladas por ellos. Por tanto, podemos afirmar que el modelo de plazos podría encuadrarse en dicha interpretación del art. 19.1, inc. $2^{\circ} \mathrm{CPR}$.

En consecuencia, la única tesis interpretativa del mandato de protección de la vida prenatal que es incompatible con un sistema de plazos es aquella que postula que proteger es equivalente a criminalizar prácticamente cualquier hipótesis voluntaria de interrupción del embarazo. Dicha interpretación tiene el apoyo de una escasa doctrina chilena (Ossandón, 2016: 269 y ss.) y era la columna vertebral de los dos requerimientos de inconstitucionalidad presentados

18 Tooley (1983) amplía de una forma más radical el ámbito temporal del estatus de nasciturus, ya que solo se puede a atribuir el estatus de persona a los seres de la especie homo sapiens a los que poseen la capacidad de ser sujetos de deseos referidos al futuro, situación que concurre a partir del tercer mes de la extrauterina. Mañalich (2014: 321-325), si bien manifiesta que esta posición resulta «inatacable en el nivel de la sola fundamentación moral», desde el punto de vista de la "praxis cotidiana» y del principio de precaución resulta adecuado establecer el comienzo del estatus normativo de persona desde el nacimiento. 
contra el proyecto de despenalización de la interrupción del embarazo en tres causales.

\section{LA CONSTITUCIONALIZACIÓN DE LOS DERECHOS REPRODUCTIVOS DE LA MUJER}

El TC se hace eco de la tendencia en el derecho, tanto nacional como internacional, de enunciar y reconocer la existencia de derechos fundamentales ${ }^{19}$ propios, específicos y exclusivos para determinados grupos o sectores de la sociedad. Dentro de estos derechos específicos destacan los derechos reproductivos asociados a la maternidad. Pese a no estar consagrados, en general, en las cartas constitucionales ni en los tratados internacionales (con excepción de la CEDAW), estos derechos han sido desarrollados por órganos internacionales y tribunales nacionales como derechos implícitos. En el nivel interamericano, por ejemplo, la sentencia de la Corte IDH en el caso Artavia Murillo v. Costa Rica (2012) fundó el derecho de acceso a tratamientos de fertilización in vitro en una serie de derechos contemplados en la Convención Americana de Derechos Humanos, a saber, el derecho a la integridad personal, la libertad personal, la intimidad, el derecho a fundar una familia y el derecho a la igualdad. La STC sobre indicaciones hace una remisión general a «los tratados internacionales» relacionados con el embarazo y la maternidad sin identificarlos, mientras que alude al Sistema Interamericano de Protección de Derechos Humanos y, en particular, al caso Artavia Murillo, como uno más de los antecedentes de protección de los derechos reproductivos y sexuales de la mujer en el derecho comparado e internacional ${ }^{20}$.

19 La doctrina y la jurisprudencia chilenas habitualmente usan la expresión derechos fundamentales para referirse a los derechos formalmente reconocidos en la Constitución, a aquellos contenidos en tratados internacionales ratificados por Chile y a los derechos implícitos establecidos por vía interpretativa; por aplicación del art. $5^{\circ}$ y del encabezado del art. 19 de la Constitución chilena, que establecen, en conjunto, que son límites de la soberanía los derechos que emanan de la naturaleza humana que estén consagrados en la Constitución o en tratados internacionales y que la titularidad de esos derechos recae en las personas (no en los ciudadanos). En consecuencia -y con la sola excepción de cierta doctrina específica-, las expresiones derechos fundamentales, derechos constitucionales y derechos humanos se utilizan de manera relativamente intercambiable. Así también se hace en este trabajo.

$20 \mathrm{CIDH}$, caso Artavia Murillo y otros vs. Costa Rica, Sentencia de 28 de noviembre de 2012, Serie C 257); CIDH, medidas provisionales respecto de El Salvador. Asunto B 29 de 29 de mayo de 2013; Comisión IDH en la que exhortó a Paraguay a asegurar la vida e integridad física de la niña Manuimby (2015). 
A pesar de la generalidad del examen realizado sobre las normas internacionales relativas a los derechos reproductivos, a diferencia de su fallo sobre la píldora del día después, en la STC sobre indicaciones el TC se sirve de diferentes normas constitucionales y legales para justificar la protección de estos derechos en el ordenamiento chileno. En los considerandos 35 a 38 de esta sentencia menciona algunos derechos fundamentales tradicionales que concurren en la regulación del aborto, como el derecho a la vida e integridad física, el derecho a la salud, el derecho a la privacidad y la prohibición de toda discriminación arbitraria. También toma nota del surgimiento de nuevos derechos que han permitido la especificación de los referidos derechos tradicionales a la situación de las mujeres. A saber, la protección efectiva contra todo acto de discriminación, el derecho a ser valorada y educada libre de patrones estereotipados de comportamiento y prácticas sociales culturales basadas en conceptos de inferioridad o subordinación, el derecho a una vida libre de violencia física, sexual y psicológica, y el derecho a una capacidad jurídica idéntica a la del hombre. Dentro de estos últimos, el TC inscribe las protecciones relacionadas con la maternidad, entre otras, el derecho a acceder a servicios adecuados de atención médica, inclusive información, asesoramiento y servicios en materia de planificación de la familia, y a decidir libre y responsablemente respecto del número de sus hijos y el intervalo entre los nacimientos (cons. 38). El último considerando de la STC sobre indicaciones caracteriza el embarazo como «un estado temporal, propio de la mujer, normalmente voluntario, personalísimo, que compromete el cuerpo de la mujer. El embarazo compromete la integridad física y psíquica de la mujer, pues, entre otras cosas, el feto ocupa su cuerpo y provoca transformaciones físicas y fisiológicas» (cons. 39).

Los derechos sexuales y reproductivos de la mujer son una manifestación concreta de la dignidad y autonomía femeninas. Los debates sobre el aborto han tenido una importancia crucial en el asentamiento de estos derechos. Primero, cobijando demandas de despenalización acotadas a permisos excepcionales de interrupción del embarazo y fundadas en razones de salud pública o de igualdad de clase, para luego hacerse eco de las demandas feministas de derogación general de la prohibición penal del aborto, basadas medularmente en la autonomía procreativa femenina (Siegel, 2016). Este cambio de orientación del tratamiento del aborto, desde la excepción al derecho, se ha expresado en un notable cambio de su técnica regulativa. Como apunta Cook (1991: 90) ya entre los años ochenta y noventa del siglo pasado, en varios países del mundo, el aborto no se regía directamente por el derecho penal, el cual ha sido reemplazado por regulaciones civiles y administrativas que consideran al aborto una intervención médica rutinaria, sujeta, incluso, a reembolso estatal. 
En consecuencia, no debe perderse de vista que las tres causales reconocidas por la ley chilena se fundamentan en situaciones de excepcionalidad que, aunque se producen en contextos reproductivos, se justifican primordialmente en la protección de otros derechos distintos a la autonomía procreativa. En el caso de la causal terapéutica se protege la vida de la gestante, mientras que, en los casos de la inviabilidad fetal de carácter letal y violación, la protección recae usualmente en la integridad psíquica de la mujer. Para que se pueda interrumpir el embarazo en todos estos casos, la ley chilena exige, además del consentimiento de la interesada, la corroboración médica de la concurrencia de la causal, al tiempo que prevé la existencia de un régimen de acompañamiento para que la mujer adopte la decisión. Puede decirse, entonces, que este modelo de indicaciones no orbita, en realidad, alrededor de la autonomía de mujer. Antes bien, parte del alto valor de la vida prenatal cuyas excepciones son ponderadas y aplicadas por terceras personas, en el que el papel de la mujer queda reducido al de mera solicitud de una intervención médica cuya oportunidad y necesidad deciden otros (Laurenzo, 2012: 6).

En contraste, el modelo de plazos sin expresión de causa incorpora la visión de género en la problemática del embarazo, en especial, respecto de su autonomía personal. Da cuenta específicamente de la implicación física y personal del embarazo, y distingue entre el hecho biológico del embarazo y el hecho personal y social de la maternidad. También da una respuesta a las mujeres más vulnerables, es decir, aquellas que encuentran más dificultades para acceder a un sexo, medidas anticonceptivas y aborto seguros, facilitando un mejor acceso a los servicios y programas de salud sexual y reproductivos (ibid.: 6-7).

En el ordenamiento chileno, la constitucionalidad de un modelo de plazos requiere, desde la perspectiva de los derechos sexuales y reproductivos de la mujer, un proceso de adscripción de estos a una disposición constitucional. Entre otras normas, el derecho a decidir sobre el embarazo, como una manifestación de la autonomía reproductiva de la mujer, puede entenderse adscrito a los arts. 1, inciso 1, 19, No 2, inciso, parte final, y 19 No 4 CPR, que consagran, respectivamente, el principio de autonomía, el derecho de igualdad entre hombres y mujeres, y la protección de la vida privada.

Además, debemos recordar que la concreción de los derechos sexuales y reproductivos de la mujer no se agota en establecer un límite al poder sancionatorio del Estado, sino que conlleva aparejado un derecho social (una obligación positiva de prestación). En este sentido, el Tribunal Europeo de Derechos Humanos viene sosteniendo, en una asentada línea jurisprudencial, 
la obligación de hacer accesible a la mujer el aborto en los casos en que los Estados parte han decidido eximir de la prohibición penal ${ }^{21}$.

\section{EL ESTABLECIMIENTO DE UN PLAZO EN LA INDICACIÓN JURÍDICA}

En cuanto a los razonamientos atinentes a las diferentes causales, debemos destacar la denominada indicación jurídica, en la que se incluye, junto con el presupuesto de que el embarazo tenga como causa una agresión sexual calificada como un delito de violación, un sistema diferenciado de plazos (12 semanas como regla general y 14 semanas en los casos de menores de 14 años).

El TC justifica la constitucionalidad de esta indicación con el siguiente argumento: «[...] el énfasis no tiene que estar puesto en el embrión o feto, sino en el sufrimiento de la mujer» (cons. $108^{\circ}$ ) provocado por una agresión sexual, violencia tiene el deber de evitar, de acuerdo con las convenciones internacionales (cons. 109\%).

Respecto de los plazos establecidos, el TC entiende que el establecimiento de un límite temporal hace que las mujeres violadas tomen lo antes posible una decisión para que, de esta manera, se evite el riesgo de sufrimiento que conlleva este tipo de embarazos y que aumenta a medida que avanza la gestación del nonato (cons. $110^{\circ}$ ).

Esta fundamentación contiene una contradicción difícil de soslayar: si es el riesgo de sufrimiento el que justifica esta causal, entonces no debería establecerse ningún tipo de plazo, ya que a medida que el embarazo avanza el riesgo de sufrimiento de la mujer aumenta, por tanto, debería permitirse el aborto hasta el momento en que el feto adquiere la cualidad de persona.

En contra de lo sostenido por el TC, la inclusión de unos plazos en la indicación jurídica supone implícitamente aceptar que estos poseen per se algún tipo de justificación autónoma. No debe pasar inadvertido que estos plazos concuerdan con el momento gestacional en el que se produce la denominada conexión del tálamo (el punto de entrada en el cerebro de los estímulos sensoriales) con la corteza cerebral, vital para el procesamiento sensorial. Esto supone que la justificación constitucional de la indicación jurídica no solo debe buscarse en la situación de excepcionalidad que origina el embarazo no deseado, sino también en el estatus especial que la ley otorga al nasciturus

21 Tysiac vs. Poland, 5410/03, Sentencia de 30 de marzo de 2007; A.B. \& C. vs. Irland; R.R. v. v. Poland, 27617/04, Sentencia de 26 de mayo de 2011; P. \& S. vs. Poland, 57375/08, Sentencia de 30 de octubre de 2012. 
en esta causal. De esta manera, podemos concluir que la inclusión de estos plazos en la actual ley de despenalización parcial del embarazo constituye una suerte de "caballo de Troya» que permitirá en el futuro la entrada en un modelo de plazos.

\section{LA PONDERACIÓN ENTRE LOS DERECHOS SEXUALES Y REPRODUCTIVOS DE LA MUJER Y EL NASCITURUS COMO BIEN JURÍDICO DE «LA MAYOR RELEVANCIA»}

La STC sobre indicaciones cambia drásticamente la forma de abordar la constitucionalidad de las diferentes medidas que pueden afectar de alguna manera el proceso biológico de la vida humana ${ }^{22}$. Por una parte, visibiliza por primera vez el conflicto constitucional entre la protección del que está por nacer, como «un bien jurídico de especial relevancia», y los derechos sexuales y reproductivos de la mujer y, por otra, aplica el test constitucional de proporcionalidad como mecanismo para resolver dicho conflicto. Como advierte Undurraga (2013: 108) a propósito del aborto, «el principio de proporcionalidad obliga a explicitar los beneficios y costos asociados a la protección de la vida prenatal y a cuestionarse cómo están distribuidos esos costos». Lo curioso es que el TC no aplica el test de proporcionalidad sobre la Ley 21.030, sino sobre la legislación vigente al momento de dictarse el fallo que prohibía toda clase de acción directamente encaminada a provocar un aborto ${ }^{23}$.

A continuación mencionaremos aquellos razonamientos relacionados con el test de proporcionalidad comprendidos en el breve capítulo del fallo dedicado expresamente a esta forma de control de constitucionalidad (cons. $113^{\circ}-115^{\circ}$ ), y aquellos otros desperdigados en el resto de la sentencia que pueden extrapolarse a un sistema de plazos sin expresión de causa.

En primer lugar, aunque el TC no incorpora de manera expresa el principio de protección incremental del feto a la hora de aplicar el test de proporcionalidad, previamente lo ha reconocido a la hora de abordar el estatus constitucional del nasciturus y la obligación constitucional de protección de

22 La STC de la píldora del día después omitió cualquier consideración sobre las mujeres como sujetos de derechos (Zúniga y Bordalí, 2009: 177-179). Efectivamente, en la única ocasión que el TC parece hacerse cargo de los derechos de las mujeres es para degradarlos a "connotaciones afectivas muy importantes para las personas, las que son, sin duda, plenamente respetables» (STC Rol 740-2007, cons. 70).

23 Véase una propuesta de ponderación en la legislación chilena en Bascuñán (2004: 67-73). 
$e^{e s t e}{ }^{24}$. El principio de protección incremental del feto puede desplegar un papel relevante en la discusión sobre la constitucionalidad de un modelo de plazos, ya que, en un determinado espacio de tiempo, el feto no tiene ningún peso o, a lo sumo, uno insignificante $y$, por tanto, la decisión corresponde en esencia a la mujer. Correlativamente, en un momento determinado los derechos de la mujer no tienen ningún peso o, a lo sumo, uno mínimo, y, en consecuencia, pueden ser limitados.

En segundo lugar y respecto al test de idoneidad, el fallo reconoce el carácter especialmente simbólico del modelo de penalización cuasi absoluto, ya que de los aproximadamente 30.000 egresos hospitalarios por aborto anuales (sin contar con los abortos clandestinos), las sentencias condenatorias a mujeres condenadas no han superado las 150 en el periodo 2005-2016 (cons. $114^{\circ}$ ).

Si partimos de la hipótesis de que, desde un punto de vista estadístico, esta reforma va a resultar poco relevante a la hora de disminuir el número de abortos, tanto ilegales como judicializados, el diagnóstico esgrimido por el TC resulta, valga la redundancia, especialmente idóneo a la hora de justificar un sistema de plazos: tal como ocurre con un modelo prohibitivo, el actual modelo de indicaciones no cumple con la mínima idoneidad exigible a la ley. Precisamente, un razonamiento sobre la ausencia de idoneidad penal del modelo de indicaciones sirvió de fundamento al TC alemán para declarar la constitucionalidad del modelo de plazos ${ }^{25}$.

En cuanto al test de necesidad, que en la STC sobre indicaciones se equipara al principio de ultima ratio del derecho penal, el TC afirma que «la sanción penal absoluta del aborto, sin causales de excepción, choca con los derechos de la mujer» $y$, por tanto, no se cumpliría con el principio de necesidad respecto de la protección de uno de los derechos en conflicto (cons. 117 ${ }^{\circ}$. Esto significa, que, a priori, un modelo de plazos cumpliría con el subprincipio de necesidad, ya que este modelo no supone un desequilibrio irracional en comparación con otras medidas de control social a la hora de alcanzar el objetivo propuesto por la norma. Si el objetivo de un modelo de plazos reside en reconocer en un periodo de la gestación (en nuestra propuesta, 14 semanas) el ejercicio pleno de los derechos y deberes reproductivos de la mujer y minimizar

24 El TC, tras poner de relevancia la prevalencia de la vida de la mujer o de la carga que supone el embarazo producido de una violación, manifiesta que, «a partir de cierto límite, los derechos de la mujer deben primar» (cons. 78).

25 BverGE, 88, 203, Sentencia de 28 de mayo de 1993. Como suele suceder en la aplicación de los modelos de indicaciones, este devino una modelo de plazos en encubierto (Bascuñán, 2001: 228). 
la afectación del nasciturus, resulta difícil encontrar otro medio alternativo que, de forma clara, sea más idóneo. Como hemos mencionado, estamos ante uno de los modelos más conservadores de despenalización del aborto en el que se otorga un papel relevante a la autonomía de la mujer.

Finalmente, en relación con el subprincipio de proporcionalidad en sentido estricto, el TC reconoce que el embarazo implica un compromiso vital de la mujer que la afecta durante toda su vida dado el carácter único del vínculo de la maternidad (cons. 108 ${ }^{\circ}$ ). Es evidente que los impactos del embarazo no se circunscriben a los casos de indicaciones, ni siquiera a los más intensos, y en su valoración no solo debe considerar la afectación material de derechos, sino también su dimensión simbólica, en el sentido de que las normas punitivas refuerzan los significados sociales estigmatizadores del aborto (Cook, 2016). Por estas y otras razones, la jurisprudencia constitucional comparada ha ido aceptando progresivamente los sistemas de plazo como una forma apropiada de armonizar los diferentes intereses o derechos en juego.

Analizados los razonamientos de la STC de indicaciones, pasamos a mencionar algunas consideraciones adicionales sobre la proporcionalidad del modelo de plazos.

En primer lugar, y de acuerdo con Bascuñán, la relevancia del test de proporcionalidad resulta secundaria respecto a la calificación de los derechos y bienes constitucionales en abstracto. Si se le asigna al nonato el estatus de un titular de derecho a la vida, entonces el juicio de ponderación se inclinará a su favor, dejando abierta la posibilidad de otorgar en situaciones excepcionales un mayor peso a los derechos de la gestante. $Y$ a la inversa, si se reconoce a la mujer un derecho robusto a su autonomía reproductiva y no se reconoce al nonato un derecho a la vida, entonces el juicio de ponderación se inclina a favor del ejercicio del primero, dejando la posibilidad de una limitación legal de su ejercicio extemporáneo (Bascuñán, 2016: 181).

En segundo lugar, debemos señalar que el establecimiento de un plazo a la hora de llevar a cabo una interrupción del embarazo supone un importante límite a los derechos sexuales y reproductivos de las mujeres. La tesis planteada en este estudio es que, a partir de las 14 semanas, el embrión adquiere el estatus de bien jurídico penal (estatus constitucional-penal) y, por tanto, con anterioridad al vencimiento de este plazo la decisión de continuar con el embarazo cae, principalmente, en el ámbito del ejercicio de los derechos sexuales y reproductivos de la mujer. La protección del que está por nacer antes de las 14 semanas de gestación (estatus constitucional general) se articula a partir de una serie de medidas tales como las destinadas a reducir los embarazos no deseados o a garantizar una decisión reflexiva. Pasado este plazo, los derechos de la mujer ceden protagonismo a la vida prenatal, entendida esta en palabras del TC como un «bien jurídico de la mayor relevancia», con una 
protección penal que solo puede ceder ante casos excepcionales. Aquí, la tutela penal se refuerza cuando se inicia la fase de viabilidad extrauterina, ya que las 23 semanas de gestación constituye el periodo general de vigencia para aplicar las indicaciones terapéuticas y embriopática. Pasado este periodo, se produce otro reforzamiento de la protección penal, ya que solo cabría la aplicación de las causas generales de exclusión de la responsabilidad penal.

En tercer lugar, resulta importante discutir, desde el punto de vista estructural, ante qué tipo de conflicto constitucional nos encontramos. A nuestro entender, el conflicto constitucional que subyace a la regulación del aborto no debe ser comprendido como un mandato de optimización (Alexy, 2003: 109, 118-122) o, al menos, tal tesis debería matizarse. Aquí cobra relevancia la clasificación de los principios en directrices y principios en sentido estricto $^{26}$. Cuando estamos ante un conflicto entre principios en sentido estricto no puede operar el mandato de optimización en cada uno de los casos genéricos que se presentan, sino que estos deben respetarse de forma general, en el sentido de que, a la vista del conjunto de conflictos constitucionales, no exista un grave desequilibrio en la protección de un principio respecto del otro. Así, en nuestra propuesta, la interrupción voluntaria del embarazo presenta varios casos genéricos: antes de la concepción o de la anidación ${ }^{27}$, hasta las primeras catorce semanas, situaciones excepcionales como las indicaciones terapéutica y embriopática, etc. Es a la luz del conjunto de estos casos que debe determinarse si existe una prevalencia desproporcionada de uno de los principios en sentido estricto en conflicto. Nuestra respuesta es que con un modelo de plazos la protección de la vida prenatal se encuentra suficientemente asegurada e, incluso, podemos afirmar que existe una prevalencia de esta respecto de los derechos reproductivos de la mujer. En efecto, de las aproximadas cuarenta semanas de gestación de un embarazo, solo en las 14 primeras semanas prevalecen los derechos reproductivos de la mujer, y con posterioridad a este plazo estos derechos u otros asociados a la mujer, como el derecho a la vida o a la integridad física, prevalecen solo en casos excepcionales (indicaciones o causas generales de exención de la responsabilidad penal).

Como veremos, la tesis antes planteada es perfectamente compatible con los estándares interamericanos sobre derechos sexuales y reproductivos.

\footnotetext{
26 Las siguientes líneas toman como referencia a Atienza y Manero (2007: 24-50).

27 En el caso Artavia Murillo la Corte IDH sostuvo que la Corte resalta que el embrión, antes de la implantación, no está comprendido en los términos del art. 4 de la Convención y recuerda el principio de protección gradual e incremental de la vida prenatal (párr. 315).
} 


\section{EL SISTEMA INTERAMERICANO DE PROTECCIÓN DE DERECHOS HUMANOS}

Tanto la Comisión Interamericana de Derechos Humanos (Comisión IDH) como la Corte Interamericana de Derechos Humanos (Corte IDH), en el marco de sus respectivas competencias, han abordado la especial precariedad de los derechos sexuales y reproductivos de las mujeres en el contexto regional americano.

La Comisión IDH, a través de sus Informes anuales por países ${ }^{28}$ y temáticos, y del trabajo de su Relatoría sobre derechos de la mujer, ha manifestado reiteradamente su preocupación por el impacto de las restricciones punitivas al aborto en la salud reproductiva de las mujeres y en el resto de sus derechos. En su Informe Estándares jurídicos vinculados a la igualdad de género y a los derechos de las mujeres en el sistema interamericano de derechos humanos: desarrollo y aplicación (2011: 144), la Comisión IDH destaca las diversas barreras que afectan a las mujeres en relación con sus derechos reproductivos y reitera la obligación de emprender:

[...] una revisión detallada de todas las leyes, normas prácticas y políticas públicas cuya redacción o implementación práctica pueda tener repercusiones discriminatorias en el acceso de las mujeres a los servicios de salud reproductiva; su deber de eliminar todos los obstáculos de jure y de facto que impiden el acceso de las mujeres a los servicios de salud materna que requieren, como su penalización; y tomar en cuenta que las leyes restrictivas tienden a tener un efecto especial en las niñas y mujeres afectadas por la pobreza, que tienen bajos niveles de educación y viven en zonas rurales.

Hasta ahora, el Sistema Interamericano de Derechos Humanos no se ha pronunciado sobre ningún asunto de fondo referido específicamente a la compatibilidad de las leyes latinoamericanas que penalizan el aborto con la Convención Americana de Derechos Humanos (CADH) o con la Convención de Belém do Pará.

La Comisión IDH se ha pronunciado sobre la compatibilidad de las leyes que despenalizan el aborto en relación con la Declaración Americana de Derechos Humanos, pero no respecto de la CADH. En el caso Baby Boy vs EEUU (1981), ante el alegato de los peticionarios que sostenían que el derecho a la vida consagrado en la declaración protegía de manera amplia a los seres humanos y no solo a las personas, la Comisión IDH sostuvo que, al adoptar la referida declaración, los Estados signatarios no adoptaron ninguna

28 En este sentido, los Informes sobre México (1997), Colombia (1999), Perú (2000) y Guatemala (2001). 
posición respecto del momento en que comenzaba la tutela de la vida. En el conocido caso Paulina (2007) se cuestionaba el efectivo cumplimiento de un régimen de indicaciones y su repercusión sobre los derechos consagrados en la $\mathrm{CADH}$. Sin embargo, este caso se resolvió mediante solución amistosa, en la que el Estado reconoció la afectación de los derechos reproductivos de una menor de edad, embarazada a consecuencia de una violación, a la que se le obstaculizó el acceso a servicios de aborto garantizados por la ley mexicana.

A solicitud de la Comisión IDH, la Corte IDH ha conocido solo un caso relacionado con las leyes de aborto, pero en el marco de una medida provisional. Se trata del caso Asunto B. contra Salvador (2013). La solicitud de medidas provisionales se presentó por la Comisión IDH debido a la negativa estatal de permitir un aborto pese al riesgo vital que afectaba a la gestante y a la falta de viabilidad del feto. Dicha negativa se fundó en la existencia de una legislación interna que criminalizaba todas las hipótesis de aborto. Sin pronunciarse sobre si tal legislación resultaba compatible o no con la $\mathrm{CADH}$, la Corte IDH resolvió:

[...] requerir al Estado de El Salvador que adopte y garantice, de manera urgente, todas las medidas que sean necesarias y efectivas para que el grupo médico tratante de la señora B. pueda adoptar, sin interferencia alguna, las medidas médicas que se consideren oportunas y convenientes para asegurar la debida protección de los derechos consagrados en los artículos 4 y 5 de la Convención Americana y, de este modo, evitar daños que pudiesen llegar a ser irreparables a los derechos a la vida y la integridad personal y a la salud de la señora B., conforme a lo expresado en los párrafos considerativos 11 a 17 de la presente Resolución.

No obstante lo anterior, tanto la Comisión IDH como la Corte IDH han ido perfilando, a través de sus intervenciones en controversias relacionadas con dimensiones procreativas distintas a la interrupción del embarazo, una jurisprudencia que permite extraer estándares interamericanos sobre los derechos sexuales y reproductivos y derivar algunas conclusiones en relación con los diferentes tipos de regulación estatal sobre el aborto.

El uso recurrente de una interpretación dinámica de la $\mathrm{CADH}$, unido a su interpretación a la luz de otros tratados del sistema regional americano (en especial, la Convención de Belem do Pará) y del sistema universal (la CEDAW), han favorecido el desarrollo de una doctrina innovadora y expansiva sobre estos derechos en el sistema interamericano. En particular, la Corte IDH ha aplicado su doctrina de la diligencia estatal reforzada, desarrollada para casos de violencia de género, ha protegido de manera expresa la indemnidad 
sexual $^{29}$ y reproductiva ${ }^{30}$ de las mujeres, ha reconocido la autodeterminación procreativa femenina en lo concerniente a los tratamientos de salud reproductiva $^{31}$ y ha reprochado la instrumentalización de los cuerpos femeninos ${ }^{32}$.

Lo mismo que en el derecho constitucional comparado, en la jurisprudencia interamericana los derechos sexuales y reproductivos son concebidos como derechos implícitos, con carácter mixto. Es decir, implican prohibiciones de interferencia estatal y también obligaciones de carácter prestacional. En el asunto Artavia Murillo vs Costa Rica (2012) aparece muy claramente desarrollada esta doctrina. La Corte IDH sostuvo que la decisión de ser o no madre o padre es parte del derecho a la vida privada e incluye la decisión de ser madre o padre en el sentido genético o biológico (párr. 143), mientras que el derecho a la vida privada se relaciona con: i) la autonomía reproductiva, y ii) el acceso a servicios de salud reproductiva, lo cual involucra el derecho de acceder a la tecnología médica necesaria para ejercer ese derecho (párr. 146).

Por otra parte, resulta claro que, en el contexto interamericano, los derechos sexuales y reproductivos de las mujeres y del colectivo LGBTI están íntimamente vinculados a las exigencias de la igualdad, y que este último principio se concibe como una norma de ius $\operatorname{cogens}^{33}$ que no admite acuerdo en contrario. Tal concepción no deja espacio a la doctrina del margen de apreciación, usada por el Tribunal Europeo de Derechos Humanos para resolver, entre otros casos, asuntos relacionados con la criminalización del aborto ${ }^{34}$. La Corte IDH, en cambio, ha rechazado reiteradamente aplicar esta doctrina ${ }^{35}$, por lo que es altamente probable que, de presentarse un caso sobre la compatibilidad de la punición del aborto con la CADH y otros tratados regionales, adoptaría la misma postura. Refuerza lo anterior el pronunciamiento sin ambages que sobre el estatuto del nasciturus realizó en el caso Artavia Murillo.

Para apreciar la gravitación del caso Artavia Murillo en los debates sobre la criminalización del aborto en Latinoamérica es importante tener presente

29 Véase Gonzáles y otras (Campo Algodonero) vs. México (2009), Rosendo Cantú y otra vs. México (2010), Fernández Ortega y otros vs. México (2011) y Velásquez Paiz y otros vs. Guatemala (2015).

30 Véanse Penal Castro vs. Perú (2006), Masacre de las dos RR vs. Guatemala (2009).

31 Véase I.V. vs. Bolivia (2016) sobre esterilización forzada y consentimiento previo e informado.

32 Véase Gelman vs. Uruguay (2011), a propósito de la sustracción de niños y niñas por parte de las dictaduras latinoamericanas.

33 Véase Atala Riffo e hijas vs. Chile (2012).

34 Véase $A B C$ vs. Irlanda, Sentencia de 17 de diciembre 2010, R.R. vs. Polonia, Sentencia de 26.05. 2011, y P. y S. v. Polonia, Sentencia de 30.10.2012.

35 Véase, entre otros casos, Atala Riffo e hijas vs. Chile (2012), Fornerón vs. Argentina. 
que uno de los expedientes más utilizados en la región para impugnar la constitucionalidad de leyes y políticas públicas destinadas a reforzar la autonomía procreativa de las mujeres ha sido, precisamente, lo dispuesto en el art. 4.1 de la CADH. Esta disposición establece que «el derecho a la vida estará protegido por ley, en general, a partir del momento de la concepción». Con eje en esta norma se ha logrado instalar una jurisprudencia constitucional que, trascendiendo las discusiones sobre el aborto, ha obstaculizado el acceso a la fecundación in vitro ${ }^{36} \mathrm{y}$ a la anticoncepción de emergencia ${ }^{37}$.

En su sentencia en el caso Artavia Murillo, la Corte IDH aclaró que «el objeto y fin de la cláusula "en general" del artículo 4.1 de la Convención es la de permitir, según corresponda, un adecuado balance entre derechos e intereses en conflicto» (párr. 263) y descartó explícitamente que la citada norma deba interpretarse en el sentido de conferir el estatus de persona al nonato. Sostuvo, en cambio, que «la "concepción" en el sentido del artículo 4.1 tiene lugar desde el momento en que el embrión se implanta en el útero, razón por la cual antes de este evento no habría lugar a la aplicación del artículo 4 de la Convención» (párr. 264); y agregó que «la protección del derecho a la vida con arreglo a dicha disposición no es absoluta, sino gradual e incremental según su desarrollo, debido a que no constituye un deber absoluto e incondicional, sino que implica entender la procedencia de excepciones a la regla general» (párr. 264). Dicha protección debe ser compatible con los derechos sexuales y reproductivos de las mujeres porque las regulaciones procreativas tienen un impacto diferenciado y desproporcionado sobre estas; afectando, además de sus derechos procreativos, el principio de igualdad (párrs. 294 a 302).

Artavia Murillo abrió las puertas a la impugnación de las leyes severamente restrictivas del aborto, por su incompatibilidad con la CADH. Lo

36 La sentencia de la Corte Suprema de Costa Rica (2000-02306) que dio origen al caso Artavia Murillo sostuvo que a partir del momento en que un óvulo es fecundado existe una persona cuyo derecho a la vida es absolutamente inviolable. Según la Corte, la Fecundación in Vitro (FIV) comportaba una pérdida de embriones que no se implantarían y por tanto era incompatible con su derecho a la vida. Recientemente (2016) la IV Sala de la Corte Suprema de Costa Rica anuló un decreto del Ejecutivo que pretendía regular la FIV, como dispuso la Corte IDH en Artavia Murillo. La Corte Suprema determinó que todo lo relativo a derechos fundamentales - como el derecho a la vida y la salud de los seres humanos- es materia reservada al legislador ordinario. El TC de Chile, en su Sentencia Rol 740-2007 sobre píldora del día después, sostuvo que, al no poder descartarse un efecto abortivo del fármaco, debe prohibirse su distribución porque constituye una amenaza intolerable para la vida del nonato. El Tribunal Constitucional del Perú reprodujo prácticamente los términos del fallo chileno en su Sentencia 02005-2009. 
anterior, porque dichas leyes han descansado, en general, en una tesis constitucional que resulta incompatible con esta sentencia: el nonato es persona y su protección debe realizarse a costa de los derechos procreativos de las mujeres.

Por otra parte, sentencias recientes de la Corte IDH - como I.V. vs Bolivia (2016), sobre esterilización forzada y consentimiento informado- han afianzado la idea de que los Estados deben implementar políticas públicas respetuosas de la autonomía de las mujeres y que garanticen estrictamente el acceso igualitario y efectivo a las acciones de salud reproductiva.

Lo anterior explica la gravitación que tuvo la sentencia Artavia Murillo en el debate chileno de la Ley 21.030 que despenaliza la IVE en tres causales. Conscientes de su importancia, los requerimientos que impugnaron la referida ley ante el TC insistieron en su no aplicabilidad al sistema chileno con base en la doctrina del TC que sostiene que los tratados internacionales son infraconstitucionales. El Gobierno de Michelle Bachelet, por otro lado, así como numerosos amicus curiae, informes en derecho e intervenciones de ONGs en las audiencias públicas, sostuvieron todo lo contrario.

Aunque en la STC sobre indicaciones el TC descartó de plano pronunciarse sobre si las sentencias de tribunales internacionales o las declaraciones, observaciones o recomendaciones emanadas de los órganos internacionales repercuten en el sistema constitucional chileno (cons. $10^{\circ}$ ), mencionó explícitamente la sentencia Artavia Murillo dentro de la revisión de jurisprudencia comparada e internacional que ofrece la sentencia (cons. 19º) y citó, específicamente, el estándar de protección gradual e incremental de la vida prenatal, contemplado en Artavia Murillo como criterio relevante para resolver la cuestión.

Si bien el giro que la STC sobre indicaciones da respecto de los derechos procreativos de las mujeres, en relación con la sentencia previa sobre la pildora del día después (en la que estos derechos ni siquiera se mencionan), no puede atribuirse con certeza a la influencia de la jurisprudencia interamericana, sí es posible constatar que existe una alineación clara con esta última. Como ya señalamos, la STC sobre indicaciones descarta que el nonato sea persona. Dedica, además, un párrafo completo a justificar la afirmación de que la mujer es persona y, por tanto, sujeto de derechos. Sostiene, en particular, que la gestante no puede ser instrumentalizada, que la maternidad es un acto voluntario, no una imposición del Estado a cualquier costo (cons. 47), que las mujeres tienen autonomía moral para adoptar decisiones durante el embarazo (cons. 99) y que solo un acompañamiento no coactivo puede ser compatible con los derechos de las mujeres (cons. 111). A propósito del aborto en caso de violación, destaca que las convenciones internacionales establecen el deber del Estado de evitar la violencia física, sexual y psicológica contra la mujer (cons. 109). Asevera, por último, que la protección de la vida prenatal 
tiene sus límites en la protección de los derechos de la mujer, los que deben primar (cons. 79).

La coincidencia con la jurisprudencia interamericana es, entonces, evidente y, además, no resulta incompatible con un modelo de despenalización parcial del aborto articulado en un modelo de plazos.

\section{A MODO DE CONCLUSIÓN}

La necesidad y pertinencia de discutir la inclusión de un modelo de despenalización parcial del aborto articulado en un modelo de plazos se debe al hecho de que la principal consecuencia político-criminal y sanitaria de la reciente Ley $\mathrm{N}^{\circ} 21$ no reside en el hecho de que, en determinados contextos, el aborto en Chile se encuentre permitido y garantizado por el sistema de salud, sino en el mantenimiento de un modelo de cuasiprohibición penal simbólica sin cobertura sanitaria.

La principal conclusión de este estudio es que, de acuerdo con la STC de indicaciones, existen buenas razones a favor de la constitucionalidad de un modelo de plazos. Así, en primer lugar, este fallo incluye una serie de criterios interpretativos de corte institucional, en especial del de dinamicidad social, que resultan aplicables en un eventual control de constitucionalidad sobre una ley de plazos sin expresión de causa. En segundo lugar, el TC niega al nasciturus el estatus de persona, pero sí considera a este como un bien jurídico de especial relevancia constitucional, lo que permite sostener un modelo de protección penal diferente al establecido no solo a las personas, sino, precisamente, a los que están por nacer. En tercer lugar, si bien la STC de indicaciones no reconoce el derecho de autonomía reproductiva dentro de los derechos sexuales y reproductivos, establece una (meta) regla de ponderación entre estos derechos y el bien jurídico protegido del nasciturus. Y, en cuarto y último lugar, el Sistema Interamericano de Protección de los Derechos Humanos no establece una obligación convencional de castigar el aborto desde la concepción, sino que, por el contrario, ha reconocido y desarrollado una serie de derechos y principios interpretativos perfectamente aplicables al modelo de plazos que el modelo de plazos.

\section{Bibliografía}

Alexy, R. (2003). Tres escritos sobre los derechos fundamentales. Bogotá: Universidad Externado de Colombia. 
Atienza, M. y Ruiz Manero, J. (2007). Las piezas del derecho. Teoría de los enunciados jurídicos. Madrid: Ariel.

Bascuñán, A. (2001). Límites a la prohibición y autorización legal del aborto consentido en el derecho constitucional comparado. Revista de Derecho Público, 63, 209-247.

- (2004). La píldora del día después ante la jurisprudencia. Estudios públicos, 95, 43-89.

- (2016). Límites a la autorización legal del aborto consentido según la jurisprudencia constitucional chilena. En S. S. Ibarra, F. Zegers-Hochschildm y R. F. García-Huidobro (eds.). Aborto y derechos reproductivos: implicancias desde la ética, el derecho y la medicina (pp. 156-189). Santiago de Chile: Ediciones Universidad Diego Portales.

Bergallo, P. (2016). Interpretando derechos: la otra legalización del aborto en América Latina. En L. Casas y D. Lawson (comps.). Debates y reflexiones en torno a la despenalización del aborto en Chile (pp. 277-321). Santiago de Chile: Centro de Derechos Humanos, Universidad Diego Portales.

Comité de Derechos Humanos. L.M.R. vs. Argentina, Comunicación 168/200728 de abril de 2011.

Cook, R. (1991). Leyes y políticas sobre el aborto. Retos y oportunidades. Debate Feminista, marzo, 89-129. Disponible en: https://doi.org/10.22201/ cieg.2594066xe.1991.3.1499.

- (2016). Significados estigmatizados del derecho penal sobre el aborto. En R. Cook, J. Erdmann y B. Dickens (eds.). El aborto en el derecho transnacional. Casos y controversias (pp. 438-467). Ciudad de México: Fondo de Cultura Económica.

Dalbora, J. L. (2012). Aborto: delito arcaico, punibilidad regresiva y explotación social. Revista de Estudios de la Justicia, 17, 17-51.

Dides, C. et al. (2016). Aborto en Chile: cifras y testimonios que respaldan la exigencia de la legalización del aborto. Revista Nomadías, 20, 145-187.

Doctor on Fetal Pain (2013). Fetal pain: The Evidence. Disponible en: http://www. nrlc.org/uploads/fetalpain/Fetal-Pain-The-Evidence.pdf.

Fernández, J. A. y Núñez, A. (2020). Los precedentes constitucionales chilenos del nasciturus y su compatibilidad con una ley de plazos. Doxa (en proceso de arbitraje).

Hernández, H. (2016). La legitimidad de las indicaciones del aborto y su necesario carácter de causas de justificación. En L. Casas y D. Lawson (comps.). Debates y reflexiones en torno a la despenalización del aborto en Chile (pp. 229-260). Santiago de Chile: Centro de Derechos Humanos, Universidad Diego Portales. Instituto Nacional de Estadística (2018). Sintesis de resultados: censo 2017, 2018. Disponible en: https://bit.ly/2ytGx5V.

Laurenzo, P. (2012). El aborto no punible en Dogmática y política criminal del aborto. Valencia: Tirant lo Blanch. 
Lee, S. (2005). Fetal Pain. A Systematic Multidisciplinary Review of the Evidence. Clinical Review, 294 (8), 947-954. Disponible en: https://doi.org/10.1001/ jama.294.8.947.

Mañalich, J.P (2014). La permisibilidad del aborto como problema ontológico. Derecho y Humanidades, 23, 305-333.

Ossandón, M. M. (2016). Aborto cuando el embarazo es resultado de una violación: un injusto penal eventualmente no exigible. En L. Casas y D. Lawson (comps.). Debates y reflexiones en torno a la despenalización del aborto en Chile (pp. 229260). Santiago de Chile: Centro de Derechos Humanos, Universidad Diego Portales.

Paez, E. (2015). Are We Animals? Abortion, Identity and Modified Futuro-of-Value account. Dilemata, 18, 243-258.

Queralt, J. (2011). La regulación del aborto en España tras la Ley Orgánica 2/2010. La Ley, 81, 1-22.

Rubenfeld, J. (1991). On the Legal Status of the Proposition that «Life Begins at Conception». Stanford Law Review, 43, 599-623. Disponible en: http://digitalcommons.law.yale.edu/fss_papers/1568.

Siegel, R. (2016). La constitucionalización del aborto. En R. Cook, J. Erdmann y B. Dickens (eds.). El aborto en el derecho transnacional. Casos y controversias (pp. 27-57). Ciudad de México: Fondo de Cultura Económica.

Tooley, M. (1983). Abortion and Infanticide. Oxford: Clarendon Press.

Undurraga, V. (2013). Aborto y protección del que está por nacer en la Constitución chilena. Santiago de Chile: Thomson Reuters.

Willenmann, J. et al. (2017). Control de Constitucionalidad del Proyecto de Ley que regula la despenalización de la interrupción voluntaria del embarazo en tres causales, correspondiente al Boletín 9895-1l (Amicus curiae presentado al TC). Disponible en: https://doi.org/10.7764/RLDR.5.59.

Zúñiga, Y. (2018). Los debates sobre el aborto. Paradojas, narrativas y dispositivos de poder-saber. Anales de la Cátedra Francisco Suárez, 52, 99-112.

Zúñiga, Y. y Bordalí, A. (2009). Análisis del fallo del Tribunal Constitucional sobre la píldora del día después. Anuario de Derecho Humanos. Santiago de Chile: Centro de Derechos Humanos de la Universidad Austral de Chile, 173-182. 